\title{
Prevalence of Lipitension in Kashmir North India: A Hospital Based Study
}

\author{
Mushtaq Ahmad, M.D.*; Fayaz Ahmad Sofi, M.D.**; Shariq Rashid Masoodi, M.D., D.M.*** \\ *Associate Professor, Department of Internal Medicine \\ **Additional Professor, Department of Internal Medicine \\ ****Professor, Department of Endocrinology \\ Sher-i-Kashmir Institute of Medical Sciences, Srinagar, Jammu and Kashmir, India.
}

\section{A B S T R A C T}

2 years hospital based prospective study was undertaken. 200 patients of hypertension and 150 normotensives were studied for abnormal lipid parameters. $72 \%$ hypertensives and 63.3\% of normotensives were found to have Dyslipidaemia as per NCEPATPIII. JMS 2014; $17(2): 59-60$ Keywords: Lipitension, Dyslipidaemia, Hypertension.

\section{INTRODUCTION}

Hypertension can cause damage to all organs of the body. Dyslipidaemia and Hypertension are the commonest risk factors for coronary artery disease. The combination of Hypertension and Dyslipidaemia (Lipitension) are particularly at high risk of CAD. So during work up of hypertensive patients it is worth while to investigate all side factors of CAD. The study was therefore carried out to know the abnormal lipid profile prevalence and pattern among hypertensive patients.

\section{METHODS}

A prospective study of 2 years was undertaken. 200 patients of hypertension who were attending medical OPD for treatment were randomly picked for the study. 150 subjects of normal blood pressure who had attended OPD for medical check-up were also randomly picked up for the study. Patients with CRF, diabetes mellitus, hypothyroidism, CLD as well as patients on oral contraceptives, statins and ethanol users were not taken into study (excluded from study and control groups). The blood pressure recording was taken in right arm after 5 minutes of rest.12 hour fasting blood samples were taken from the subjects.

The following parameters were measured:

1. Total cholesterol in $\mathrm{mg} / \mathrm{dl}$.

2. HDL cholesterol in $\mathrm{mg} / \mathrm{dl}$.

\section{Correspondence \\ Dr. Mushtaq Ahmad, M.D. \\ Assistant Professor, \\ Department of Internal Medicine, \\ SKIMS Srinagar Kashmir. \\ drmushtaq_01@yahoo.co.in}

\section{Triglycerides in $\mathrm{mg} / \mathrm{dl}$.}

LDL cholesterol was calculated by Friendwald formula i.e. $\mathrm{LDL}=$ total cholesterol-[HDL+TG/5].

Individuals were classified on the basis of national cholesterol education program (NCEP) adult treatment panel III .Data analysis was expressed as the mean value + SD. Statistical analysis was done by using t-test and chisquare test. The $\mathrm{p}$ value of $<0.05$ was taken as value of statistical significance.

\section{RESULTS}

In hypertensive group $88(44 \%)$ were males and $112(56 \%)$ were females with age range of 16-75 years and mean of $44.9+11.9$ years. In control group out of total of 150 subjects $42(28 \%)$ were males and $108(72 \%)$ were females with age range $16-80$ years and mean of $41.6+11.6$ years. $144(72 \%)$ hypertensives were found to have cholesterol $>200 \mathrm{mg} / \mathrm{dl}$; LDL $>100 \mathrm{mg} / \mathrm{dl} ; \mathrm{TG}>150 \mathrm{mg} / \mathrm{dl}$ and $\mathrm{HDL}<40 \mathrm{mg} / \mathrm{dl}$ as compared to $95(63.3 \%)$ in normotensives. The results are shown in table 1 and bar table given below:

Table 1: Dyslipidemia (As per NCEP ATP 111)

\begin{tabular}{|c|l|lr|lr|l|}
\hline S.No. & \multicolumn{1}{|c|}{ Types } & \multicolumn{2}{|c|}{ Hypertensive } & \multicolumn{2}{|c|}{ Controls } & p-Value \\
\hline 1. & TC $(\geq 200 \mathrm{mg} / \mathrm{dl})$ & 94 & $74.0 \%$ & 56 & $37.3 \%$ & 0.177 \\
\hline 2. & LDL $(\geq 100 \mathrm{mg} / \mathrm{dl})$ & 122 & $61.0 \%$ & 75 & $50.0 \%$ & 0.079 \\
\hline 3. & TG $(\geq 150 \mathrm{mg} / \mathrm{dl})$ & 151 & $75.5 \%$ & 92 & $61.3 \%$ & 0.044 \\
\hline 4. & HDL $(<40 \mathrm{mg} / \mathrm{dl})$ & 73 & $36.5 \%$ & 35 & $23.3 \%$ & $0.015^{*}$ \\
\hline
\end{tabular}

Table 2: Comparison of prevalence of dyslipidemia with other studies

\begin{tabular}{|l|c|}
\hline \multicolumn{1}{|c|}{ Studies } & Prevalence of Dyslipidemia \\
\hline Present study & $72 \%$ \\
\hline Pramila Devi et al & $90 \%$ \\
\hline Thakur et al & $60 \%$ \\
\hline Haskim AS et al & $40 \%$ \\
\hline
\end{tabular}




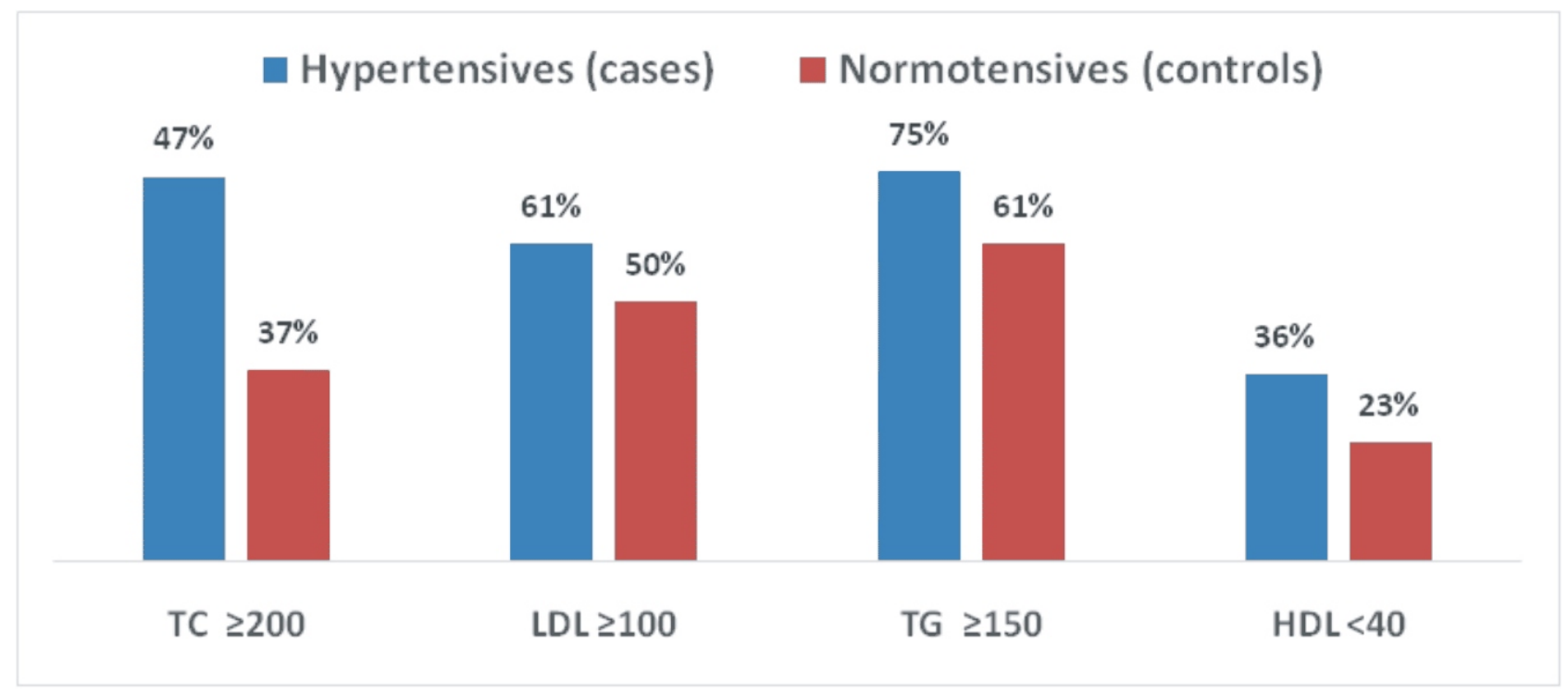

\section{DISCUSSION}

Dyslipidemia and hypertension (Lipitension) are well established risk factors for CAD and the coexistence of these have more than additive affect for the same ${ }^{1}$. The study revealed that $72 \%$ (144) of hypertensives had Dyslipidemia as per National Cholesterol Education Program (NCEP) Guidelines (Adult Treatment Panel III).

Among the controls (Normotensives) 63.3\% had Dyslipidemia as per NCEP guidelines (Adult Treatment Panel III).This study is quite apart from other studies, because lipid profile of primary hypertensives after excluding secondary causes of dyslipidemia ( like diabetes augments the process of Atherosclerosis, keeping the above lipid parameters (63.3\%). Atherosclerosis can occur without hypertension though hypertension and chronic liver disease) was estimated. As far as lipid abnormalities in hypertensives are concerned our results are comparable with results obtained by Pramila Devi.R. Et al, Tavasoli AA et al, Thakur et al $(2,3,4)$ (Table 2). As per the study of Hakim et al (1997), 68\% of patients were having elevated TC against $47 \%$ of our study (5). Our study indicates that dyslipidemia is common in hypertensives; therefore blood sampling for measuring lipid profile in hypertensives is an essential part of managing them. Our study also highlights a good number of subjects of normal blood pressure having abnormal observations in view, we conclude that healthy life style, diet and physical activity of hypertensives as well as normotensives be encouraged.

\section{REFERENCES}

1. Edward JR. National high blood pressure education program working group report on hypertension in the elderly. Hypertension 1994; 23(3): 274-85.

2. Pramila Devi $\mathrm{R}$ et al; Study of lipid profile in hypertensive patients in rural Karnataka: JPBMS, 2011, 7(18).

3. Tavasoli AA, Sadegi M, Pourmoghaddas M, Roohafza HR: Lipid profile in uncomplicated non diabetic hypertensives. Iranian heart journal 2005; 6(3): 64-69.

4. Thakur A.k, Achari A. Study of lipid levels in uncomplicated hypertension.Indian heart journal 2000; 52:173- 177.

5. Hakim AS, Kamanth SA. Mamata. A retrospective study of lipid profile in 500 hypertensive patients. J. assocphysInd 1997; 45(12): 943-44. 